\title{
ANÁLISIS CITOGEOGRÁFICO EN TURNERA KRAPOVICKASII (PASSIFLORACEAE)
}

\author{
YANINA LAZAROFF ${ }^{1}$, E. M. SARA MORENO ${ }^{1,2}$, AVELIANO FERNÁNDEZ ${ }^{1}$ y \\ VIVIANA G. SOLÍS NEFFA ${ }^{1,2}$
}

\begin{abstract}
Summary: Cytogeographic analysis in Turnera krapovikasii (Passifloraceae). Turnera krapovickasii is distributed at northwestern Argentina, southern Bolivia and western Paraguay. It presents diploid $(2 \mathrm{n}=$ $2 x=10)$ and autotetraploid $(2 n=4 x=20)$ cytotypes. Aiming to interpret the role of autopolyploidy in the evolution of this species, the frequency and spatial distribution of the cytotypes were analyzed. Equal frequencies of diploid and tetraploid populations were detected; most of them are constituted by only one cytotype, although some diploid populations presented triploid or tetraploid individuals. Diploids occupy a continuous area from southern Bolivia to northwestern Argentina, and from 124 to 1342 m.a.s.I. Tetraploids occur in disjunct areas, in Eastern and northern species area, in altitudes from 237 up to 810 m.a.s.I. The PCA showed a significant association between cytotype distribution and climate. Moreover, the ecological niche modelling analysis showed that the southeastern (Chaquenean Province) and eastern Bolivia (Cerrado Province) are the most probable areas of occurrence of diploids and tetraploids, , respectively. The cytotype distribution observed support the hypothesis that the expansion of the geographic area associated with polyploidy played an important role in the evolutionary history of T. krapovickasii.
\end{abstract}

Key words: Turnera krapovickasii, polyploidy, cytogeography

Resumen: Turnera krapovickasii se distribuye en el noroeste argentino, sur de Bolivia y oeste de Paraguay. Presenta citotipos diploide $(2 n=2 x=10)$ y autotetraploide $(2 n=4 x=20)$. A fin de interpretar el papel de la autopoliploidía en la evolución de esta especie, se analizaron la frecuencia y distribución espacial de los citotipos. Se detectaron iguales frecuencias de poblaciones diploides y tetraploides, mayormente constituidas por un solo citotipo, aunque algunas poblaciones diploides presentaron individuos triploides o tetraploides. Los diploides ocupan un área continua desde el sur de Bolivia hasta el noroeste de Argentina, y desde 124 hasta 1342 m.s.n.m. Los tetraploides ocupan áreas disyuntas, en el este y norte del área de la especie, en alturas desde 237 hasta 810 m.s.n.m. El ACP mostró una asociación significativa entre la distribución de los citotipos y el clima. Asimismo, el análisis de modelado de nicho ecológico reveló que el sureste (Provincia Chaqueña) y el este de Bolivia (Provincia del Cerrado) son las áreas de mayor probabilidad de ocurrencia de diploides y tetraploides, respectivamente. La distribución de los citotipos observada sustenta la hipótesis de que la expansión del área geográfica asociada con la poliploidía tuvo un papel importante en la historia evolutiva de T. krapovickasii.

Palabras clave: Turnera krapovickasii, poliploidía, citogeografía

\section{INTRODUCCIÓN}

La poliploidía constituye uno de los principales mecanismos de evolución y diversificación en

\footnotetext{
${ }^{1}$ Laboratorio de Citogenética y Evolución Vegetal. Instituto de Botánica del Nordeste (UNNE-CONICET). C.C. 209, 3400, Corrientes, Argentina.

${ }^{2}$ Facultad de Ciencias Exactas y Naturales y Agrimensura (UNNE).

e-mail: viviana@agr.unne.edu.ar
}

plantas (Stebbins, 1971; Ramsey \& Schemske, 1998; Soltis et al., 2004; Wendel \& Doyle, 2005). Numerosas investigaciones sugirieron que la poliploidía puede contribuir a la adquisición de características morfológicas, genéticas y/o fisiológicas nuevas (Osborn et al., 2003; Soltis et al., 2004; Adams \& Wendel, 2005a, b; Durand \& Hoberman, 2006; Chen \& Ni, 2006; Madlung, 2013), las que conferirían a los poliploides una mayor capacidad competitiva así como una mayor tolerancia o amplitud ecológica en comparación 
con la de sus progenitores diploides (Lewis, 1980; Ehrendorfer, 1980; Levin, 1983; Udall \& Wendel, 2006). En consecuencia, los poliploides pueden presentar una distribución diferente o marginal en comparación con la de los diploides a lo largo de un gradiente ambiental o climático (Levin, 2002; Husband et al. 2013).

La poliploidía es también muy frecuente en el género Turnera L. (Passifloraceae). Este género cuenta con alrededor de 135 especies americanas y dos africanas, las que fueron agrupadas en 9 series (Urban, 1883). En América, las especies de este género se distribuyen desde el sur de los Estados Unidos hasta el centro - sur de la Argentina, siendo el área comprendida en la subregión Chaqueña propuesta por Morrone (2001), la región de mayor diversificación del género (Arbo \& Espert, 2009).

Los estudios cromosómicos realizados en 35 especies (Raman \& Kesavan, 1964; Barrett, 1978; Barrett \& Shore, 1987; Arbo \& Fernández, 1983; Fernández, 1987; Solís Neffa \& Fernández, 1993; Solís Neffa, 1996; Solís Neffa \& Fernández, 2001) permitieron comprobar que en el género existen 3 números básicos $(x=5,7$ y 13) y que aproximadamente el $59 \%$ de las poblaciones analizadas hasta el momento son de origen poliploide, habiéndose detectado desde tetraploides hasta decaploides (Solís Neffa \& Fernández, 2000). Asimismo, el análisis de la meiosis de los poliploides reveló que hay alo- y autopoliploides, presentando algunas especies citotipos diploide y autopoliploide (Fernández, 1987; Shore, 1991a, b; Solís Neffa \& Fernández, 2000). Sobre la base de estos antecedentes, se ha sugerido que la poliploidía habría tenido un papel fundamental en la evolución de las especies de Turnera (Solís Neffa \& Fernández, 2000, 2001).

Actualmente, las investigaciones que se desarrollan en Turnera tienen como uno de sus objetivos interpretar los mecanismos involucrados en la dinámica evolutiva y en la diferenciación ecológica de los poliploides. En este marco, se analizaron los patrones de distribución de los citotipos del complejo Turnera sidoides $\mathrm{L}$. ( $\mathrm{x}=$ 7) de la serie Leiocarpae Urb., a distintas escalas espaciales (Solís Neffa \& Fernández, 2001; Solís Neffa, et al., 2004; Elías et al., 2011). Dichos estudios revelaron que, aunque la mayoría de las poblaciones están constituidas por un solo citotipo, también se encontraron poblaciones mixtas diploide
- poliploide (Elías et al., 2011; Kovalsky \& Solís Neffa, 2012). Teniendo en cuenta la distribución amplia de los tetraploides y la ocurrencia de los niveles de ploidía más altos en regiones que presentan las condiciones más extremas en el régimen de precipitaciones, se ha sugerido que los poliploides habrían sido colonizadores más efectivos que los diploides, habiendo desempeñado un importante papel en la expansión del área geográfica de T. sidoides (Solís Neffa \& Fernández, 2001; Solís Neffa et al., 2004; Elías et al., 2011) y posiblemente también de otras especies con citotipos diploide y autopoliploide de Turnera. Sin embargo, dado que la frecuencia y distribución de los citotipos puede variar entre grupos taxonómicos, incluso entre aquellos muy afines (Husband et al., 2013), es preciso contar con información citogeográfica de otras especies del género a fin de detectar patrones generales y de probar hipótesis acerca del papel de la poliploidía durante la historia evolutiva de las especies de Turnera.

Turnera krapovickasii Arbo $(\mathrm{x}=5)$ de la serie Turnera, constituye un interesante modelo para investigar la dinámica evolutiva de los poliploides. El área de distribución de esta especie está comprendida en una región considerada como uno de los centros más importantes de diversificación de la flora sudamericana (Gentry, 1982; Gentry \& Dodson, 1987; Moraes \& Beck, 1992; Killeen et al., 1993; Navarro \& Maldonado, 2002; Young et al., 2002). Se distribuye en el noroeste argentino, sur de Bolivia y oeste de Paraguay (Fig. 1). Se extiende entre los $16^{\circ}-21^{\circ} \mathrm{S}$ y los $59^{\circ}-65^{\circ} \mathrm{W}$ y crece en alturas desde el nivel del mar hasta los 1310 m.s.n.m. (Arbo, 2005). Desde un punto de vista biogeográfico, el área de distribución de $T$. krapovickasii comprende parte de las provincias biogeográficas del Pantanal, Cerrado y Chaqueña propuestas por Morrone (2001). Los estudios cromosómicos mostraron que las poblaciones de esta especie, analizadas hasta el momento, son diploides, $2 \mathrm{n}=2 \mathrm{x}=10$, y tetraploides, $2 \mathrm{n}=4 \mathrm{x}=20$ (Fernández, 1987; Solís Neffa \& Fernández, 1993). El análisis de la meiosis de los poliploides demostró que son autopoliploides (Fernández, 1987). El origen autopoliploide de las accesiones tetraploides fue posteriormente sustentado por un análisis filogenético empleando secuencias del genoma de cloroplastos (López et al., 2013).

Estudios preliminares revelaron que los diploides 


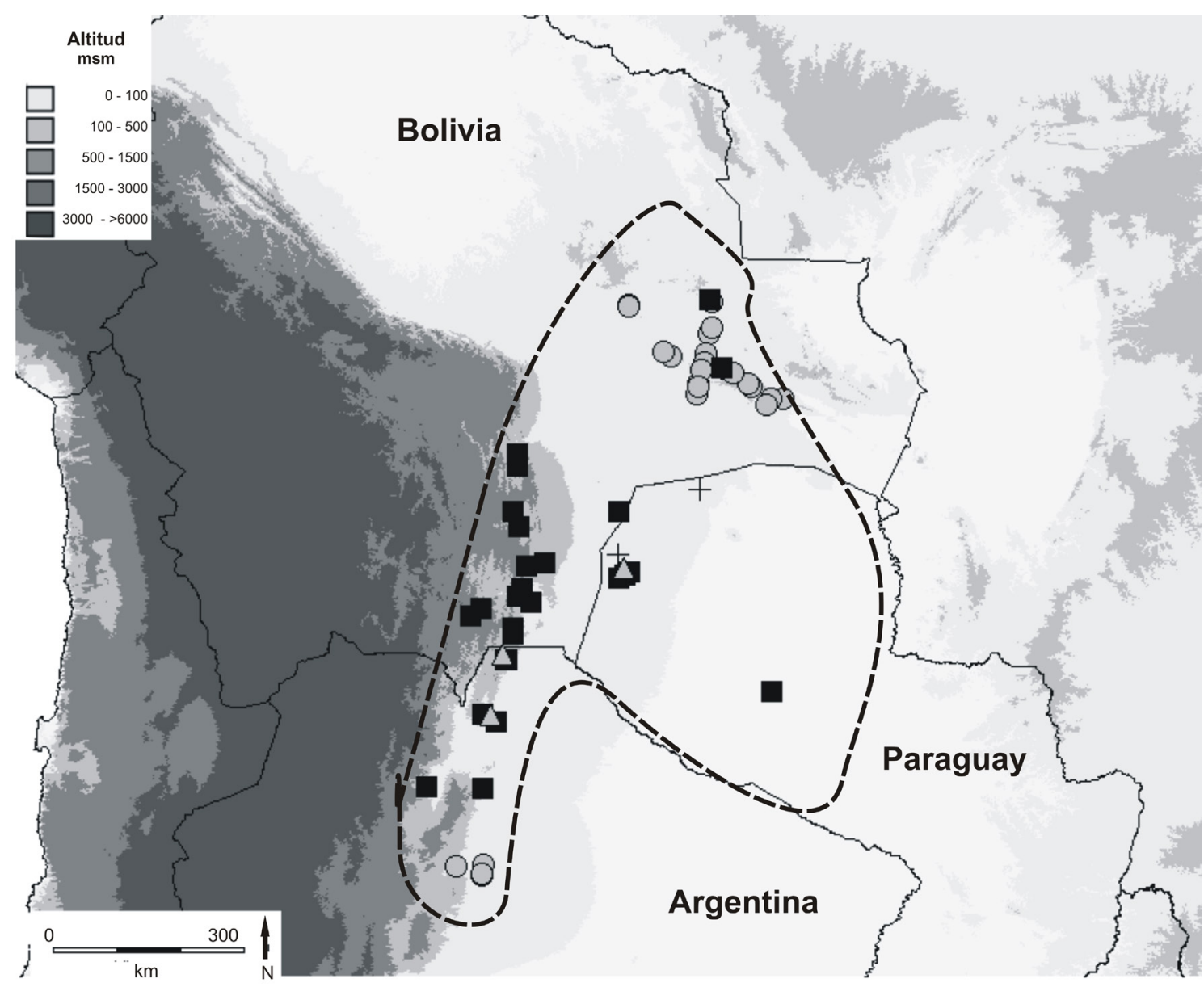

Fig. 1. Principales características geográficas de la zona de distribución de Turnera krapovickasii y distribución geográfica de los citotipos. La línea punteada indica el área de distribución de T. krapovickasii. La distribución se basa en muestras de herbario y observaciones de campo. Los distintos citotipos se indican con figuras: cuadrado $=$ diploide $(2 n=2 x=10)$; círculo $=$ tetraploide $(2 n=4 x=20)$; triángulo $=$ población mixta diploide - triploide $(2 n=3 x=15)$; cruz = población mixta diploide - tetraploide.

y tetraploides de T. krapovickasii difieren en su distribución geográfica (Reynoso et al., 2004; Lazaroff et al., 2009). Dado que el área de esta especie presenta una gran diversidad de ambientes así como tipos de vegetación relacionados a la enorme variedad climática, fisiográfica y altitudinal (Navarro \& Maldonado, 2002), la distribución de los citotipos de T. krapovickasii podría ser el resultado de diferencias adaptativas de diploides y tetraploides a la heterogeneidad ambiental. Sin embargo, hasta el momento no se ha realizado un análisis detallado sobre los factores que determinan los patrones de distribución de los citotipos en esta especie.
Por lo tanto, a fin de interpretar el papel de la autopoliploidía en la evolución de Turnera krapovickasii e inferir los factores que influyen en la distribución de los citotipos de esta especie, en este trabajo se analizan la frecuencia y distribución espacial de los citotipos en relación a variables ambientales.

\section{Materiales y Métodos}

Se analizaron 567 semillas provenientes de 59 poblaciones naturales representativas del área geográfica de Turnera krapovickasii, obtenidas 
entre los años 2005 y 2010 (Tabla 1). Algunas plantas fueron transportadas a Corrientes (Argentina), donde se cultivaron en el invernáculo del Instituto de Botánica del Nordeste (IBONE). Los ejemplares testigo de los especímenes provenientes de Argentina y Paraguay se encuentran depositados en el herbario del citado Instituto (CTES), mientras que los provenientes de Bolivia fueron depositados en el Herbario Nacional de Bolivia (LPB). Los duplicados de todos los ejemplares fueron repartidos a otros herbarios del mundo.

\section{Recuentos cromosómicos y estimación del nivel de ploidia}

Se realizaron recuentos cromosómicos en meiosis en algunos individuos de cada población, los que fueron utilizados posteriormente como patrón para analizar el nivel de ploidía de los restantes individuos de la población por citometría de flujo.

Los recuentos en meiosis se realizaron a partir de botones florales fijados en alcohol etílico absoluto: ácido láctico en una proporción 5: 1 (Fernández, 1973) y conservados en etanol $70 \%$ a $4{ }^{\circ} \mathrm{C}$. Los preparados se obtuvieron por aplastado de las anteras en carmín acético al $3 \%$.

La estimación del nivel de ploidía por citometría de flujo se realizó a partir de semillas a las que previamente se extrajo el pericarpio. Tras añadir $0,5 \mathrm{ml}$ de buffer de extracción (Partec UV kit CyStain Precise P 05-5002), las muestras fueron trituradas con una hoja de afeitar. Después de 2 min de incubación, el homogenado fue filtrado a través de una de malla de nylon de $50 \mu \mathrm{m}$ de apertura y colocadas en un tubo donde se añadieron $1,5 \mathrm{ml}$ de buffer de tinción DAPI (4',6-diamidino2-fenilindol). La mezcla fue incubada durante 2 min a temperatura ambiente y luego analizada. Las mediciones de la intensidad de fluorescencia de los núcleos teñidos con DAPI se realizaron con un citómetro de flujo Partec PA II (Partec GmbH, Münster, Alemania) con el detector funcionando a $355 \mathrm{~nm}$. Se midieron alrededor de 3000 núcleos por muestra. El análisis de los datos se realizó con el software PA II Partec Flomax.

\section{Distribución geográfica de los citotipos}

La distribución geográfica de los citotipos hallados en este trabajo junto con los obtenidos previamente por Fernández (1987), Solís Neffa
(1996) y Fernández \& Solís Neffa (2004), se representó gráficamente en un mapa confeccionado con el programa Diva-Gis (Hijmans et al., 2004). Para evaluar la posible influencia de la altitud y el clima en la distribución de los citotipos, se registró la altitud de cada localidad analizada con un GPS, mientras que las siguientes variables climáticas fueron extraídas de la base de datos WorldClim (Hijmans et al., 2005): temperatura media anual (BIO 1), rango promedio de temperatura mensual (BIO 2), isotermalidad (BIO 3), estacionalidad de temperatura (BIO 4), temperatura máxima del mes más cálido (BIO 5), temperatura mínima del mes más frío (BIO 6), rango de temperatura anual (BIO 7), temperatura media del cuatrimestre más húmedo (BIO 8), temperatura media del cuatrimestre más seco (BIO 9), temperatura media del cuatrimestre más cálido (BIO 10), temperatura media del cuatrimestre más frío (BIO 11), precipitación anual (BIO 12), precipitaciones del mes más húmedo (BIO 13), precipitaciones del mes más seco (BIO 14), estacionalidad de las precipitaciones (BIO 15), precipitaciones del cuatrimestre más húmedo (BIO 16), precipitaciones del cuatrimestre más seco (BIO 17), precipitaciones del cuatrimestre más cálido (BIO 18) y precipitaciones del cuatrimestre más frío (BIO 19).

Se realizó un análisis de componentes principales (ACP) a fin de identificar un número más reducido de variables que representen la mayor parte de la varianza de las variables climáticas entre las poblaciones. El cálculo del ACP se llevó a cabo a partir de una matriz de correlación estimada a partir del conjunto de datos estandarizados. Además, para cada citotipo, se calcularon la media, la desviación estándar promedio y el rango de variación de las variables bioclimáticas. Para evaluar las diferencias entre los citotipos se realizó un análisis multivariado de la varianza (MANOVA) a un nivel de significancia del $5 \%(\alpha=0,05)$. Además, para evaluar la existencia de diferencias significativas entre citotipos para cada una de las variables, se realizó un análisis de la varianza (ANOVA) a un nivel de significancia del $5 \%(\alpha=$ $0,05)$ luego de realizar la prueba de homogeneidad de Bartlett. Las diferencias entre cada par de medias fueron estimadas mediante el test de Tukey al 5 $\%$.Todos los análisis estadísticos fueron realizados utilizando el programa Infostat, versión 2009 (Di Rienzo et al., 2009). 
Tabla 1. Material estudiado de Turnera krapovickasii y sus niveles de ploidía. Los asteriscos ( ${ }^{*}$ ) representan estimaciones del nivel de ploidía de nuevas poblaciones. AR: Argentina, BO: Bolivia; PA:

\section{Paraguay. A.}

\begin{tabular}{|c|c|c|c|c|}
\hline Procedencia y número de colección & Lat. S & Long. O & Altitud (m.s.m.) & Ploidía \\
\hline AR, Jujuy, ruta 34, puente sobre Río Negro III. O. Ahumada 1549 (CTES). & $24^{\circ} 05^{\prime}$ & $64^{\circ} 49^{\prime}$ & 445 & $2 x$ \\
\hline $\begin{array}{l}\text { AR, Salta, Dpto. San Martín. Campo Durán. A. Panseri, W. Reynoso, M. } \\
\text { Sosa \& D. Hojsgaard } 22 \text { (CTES). }\end{array}$ & $22^{\circ} 11^{\prime}$ & $63^{\circ} 39^{\prime}$ & 465 & $2 x$ \\
\hline $\begin{array}{l}\text { AR, Salta, Río Negro III. A. Panseri, W. Reynoso, M. Sosa \& D. Hojsgaard } \\
26 \text { (CTES). }\end{array}$ & $24^{\circ} 05^{\prime}$ & $64^{\circ} 48^{\prime}$ & 441 & $2 x$ \\
\hline $\begin{array}{l}\text { AR, Salta, Dpto. San Martín. Ruta 81. A. Panseri, W. Reynoso, M. Sosa \& } \\
\text { D. Hojsgaard } 21 \text { (CTES). }\end{array}$ & $23^{\circ} 06^{\prime}$ & $63^{\circ} 47^{\prime}$ & 290 & $2 x$ \\
\hline $\begin{array}{l}\text { AR, Salta, Dpto. San Martín, camino a Maravilla. A. Panseri, W. Reynoso, } \\
\text { M. Sosa \& D. Hojsgaard } 23 \text { (CTES) }\end{array}$ & $22^{\circ} 11^{\prime}$ & $63^{\circ} 37^{\prime}$ & 473 & $2 x$ \\
\hline $\begin{array}{l}\text { AR, Salta. Ruta 81. V. Solís Neffa, G. Seijo, M. Grabiele \& W. Reynoso } 1975 \\
\text { (CTES, ASU, CESJ, ESA, FCQ, HRB, HUEM, JUA, SI). }\end{array}$ & $23^{\circ} 06^{\prime}$ & $63^{\circ} 47^{\prime}$ & 259 & $2 x$ \\
\hline $\begin{array}{l}\text { BO, Dpto. Tarija, O’ Connor, } 3 \text { km S de Entre Ríos. A. Krapovickas } 38858 \\
\text { (CTES). }\end{array}$ & $21^{\circ} 33^{\prime}$ & $64^{\circ} 10^{\prime}$ & 1342 & $2 x$ \\
\hline $\begin{array}{l}\text { BO, Dpto. Tarija, Prov. Gran Chaco, Villa Montes. A. Krapovickas } 39177 \\
\text { (CTES). }\end{array}$ & $21^{\circ} 15^{\prime}$ & $63^{\circ} 28^{\prime}$ & 445 & $2 x$ \\
\hline $\begin{array}{l}\text { BO, Dpto. Tarija, Prov. O’ Connor, } 19 \text { km E de Entre Ríos. A. Krapovickas } \\
39099 \text { (CTES). }\end{array}$ & $21^{\circ} 26^{\prime}$ & $64^{\circ} 00^{\prime}$ & 1080 & $2 x$ \\
\hline $\begin{array}{l}\text { BO, Dpto. Sta. Cruz, Prov. Cordillera. V. Solís Neffa, G. Seijo, A. Schinini \& } \\
\text { R. Almada } 1062 \text { (CTES). }\end{array}$ & $19^{\circ} 20^{\prime}$ & $63^{\circ} 29^{\prime}$ & 930 & $2 x$ \\
\hline $\begin{array}{l}\text { BO, Dpto. Tarija, Prov. Gran Chaco. V. Solís Neffa \& G. Seijo } 1482 \text { (CTES, } \\
\text { ASU, ESA, LPB, MA, MO, SI). }\end{array}$ & $21^{\circ} 09^{\prime}$ & $63^{\circ} 25^{\prime}$ & 637 & $2 x$ \\
\hline $\begin{array}{l}\text { BO, Dpto. Tarija, Prov. Gran Chaco. V. Solís Neffa, G. Seijo, M. Grabiele \& } \\
\text { W. Reynoso } 1497 \text { (CTES, LPB, SI, SP). }\end{array}$ & $21^{\circ} 48^{\prime}$ & $63^{\circ} 33^{\prime}$ & 601 & $2 x$ \\
\hline $\begin{array}{l}\text { BO, Dpto. Tarija, Prov. Gran Chaco. V. Solís Neffa, G. Seijo, M. Grabiele \& } \\
\text { W. Reynoso (CTES, ASU, BAB, ESA, FCQ, GH, HRB, HUEFS, LPB, MBM, } \\
\text { SI). }\end{array}$ & $21^{\circ} 20^{\prime}$ & $63^{\circ} 17^{\prime}$ & 340 & $2 x$ \\
\hline $\begin{array}{l}\text { BO, Dpto. Sta. Cruz, Prov. Cordillera. V. Solís Neffa, G. Seijo, M. Grabiele } \\
\text { \& W. Reynoso } 1935 \text { (CTES, ASU, ESA, FCQ, HRB, HUEM, JUA, LPB, SI, } \\
\text { SP). }\end{array}$ & $19^{\circ} 10^{\prime}$ & $63^{\circ} 29^{\prime}$ & 778 & $2 x$ \\
\hline $\begin{array}{l}\text { BO, Dpto. Sta. Cruz. Prov. Cordillera. Camiri. V. Solís Neffa, G. Seijo, A. } \\
\text { Schinini \& R. Almada } 1055 \text { (CTES, ASU, BA, CANB, LPB, MBM, MICH, SI, } \\
\text { SP). }\end{array}$ & $20^{\circ} 00^{\prime}$ & $63^{\circ} 32^{\prime}$ & 799 & $2 x$ \\
\hline $\begin{array}{l}\text { BO, Dpto. Sta. Cruz, Prov. Cordillera. V. Solís Neffa, G. Seijo, A. Schinini \& } \\
\text { R. Almada } 1432 \text { (CTES, ESA, LPB, SI, SP). }\end{array}$ & $20^{\circ} 14^{\prime}$ & $63^{\circ} 27^{\prime}$ & 675 & $2 x$ \\
\hline $\begin{array}{l}\text { BO, Dpto. Tarija, Prov. Gran Chaco. V. Solís Neffa, G. Seijo, M. Grabiele \& } \\
\text { W. Reynoso } 1503 \text { (CTES, CESJ, FCQ, HRB, LPB, NY, SI, SP). }\end{array}$ & $21^{\circ} 43^{\prime}$ & $63^{\circ} 33^{\prime}$ & 636 & $2 x$ \\
\hline $\begin{array}{l}\text { BO, Dpto. Tarija, Prov. Gran Chaco. V. Solís Neffa, G. Seijo, M. Grabiele \& } \\
\text { W. Reynoso } 1512 \text { (CTES, FCQ, GH, LPB, SI). }\end{array}$ & $21^{\circ} 10^{\prime}$ & $63^{\circ} 25^{\prime}$ & 484 & $2 x$ \\
\hline $\begin{array}{l}\text { BO, Dpto. Chuquisaca, Prov. Azero. V. Solís Neffa, G. Seijo, M. Grabiele \& } \\
\text { W. Reynoso } 1513 \text { (CTES, LPB, MO, NY, SI, SP). }\end{array}$ & $20^{\circ} 48^{\prime}$ & $63^{\circ} 20^{\prime}$ & 480 & $2 x$ \\
\hline $\begin{array}{l}\text { BO, Dpto. Sta. Cruz, Prov. Velasco. V. Solís Neffa, G. Seijo, M. Grabiele \& } \\
\text { W. Reynoso } 1743 \text { (CTES, HUEFS, LPB, SI). }\end{array}$ & $16^{\circ} 52^{\prime}$ & $60^{\circ} 38^{\prime}$ & 355 & $2 x$ \\
\hline $\begin{array}{l}\text { BO, Dpto. Tarija, Prov. Cordillera. V. Solís Neffa, G. Seijo, M. Grabiele \& W. } \\
\text { Reynoso } 1973 \text { (CTES, FCQ, HUEFS, JUA, LPB, MO, SI). }\end{array}$ & $20^{\circ} 46^{\prime}$ & $63^{\circ} 05^{\prime}$ & 676 & $2 x$ \\
\hline BO, Dpto Tarija. Prov Gran Chaco. V. Solís Neffa s/n. & $20^{\circ} 00^{\prime}$ & $63^{\circ} 32^{\prime}$ & 942 & $2 x^{*}$ \\
\hline
\end{tabular}




\begin{tabular}{|c|c|c|c|c|}
\hline Procedencia y número de colección & Lat. S & Long. $\mathrm{O}$ & Altitud (m.s.m.) & Ploidía \\
\hline PA, Dpto. Presidente Hayes. A. Krapovickas \& C. Cristóbal 44366 (CTES). & $22^{\circ} 40^{\prime}$ & $59^{\circ} 44^{\prime}$ & 124 & $2 x^{*}$ \\
\hline PA, Dpto. Boquerón. E. Zardini \& Acosta 42205 (CTES). & $20^{\circ} 54^{\prime}$ & $61^{\circ} 50^{\prime}$ & 292 & $2 x^{*}$ \\
\hline $\begin{array}{l}\text { PA, Dpto. Alto Paraguay, Sierra León. Pérez de Molas \& G. Navarro } 9077 \\
\text { (CTES). }\end{array}$ & $19^{\circ} 40^{\prime}$ & $60^{\circ} 47^{\prime}$ & 302 & $2 x^{*}$ \\
\hline $\begin{array}{l}\text { PA, Dpto. Boquerón, Ruta Transchaco. A. Krapovickas, C. Cristóbal \& A. } \\
\text { Schinini } 45380 \text { (CTES). }\end{array}$ & $20^{\circ} 56^{\prime}$ & $61^{\circ} 54^{\prime}$ & 302 & $2 x^{*}$ \\
\hline $\begin{array}{l}\text { PA, Dpto. Boquerón. A. Krapovickas, C. Cristóbal \& A. Schinini } 45462 \\
\text { (CTES). }\end{array}$ & $20^{\circ} 56^{\prime}$ & $61^{\circ} 54^{\prime}$ & 302 & $2 x^{*}$ \\
\hline PA, Dpto. Alto Paraguay, Parque Cué. F. Mereles \& Degen 5979 (CTES). & $20^{\circ} 07^{\prime}$ & $61^{\circ} 41^{\prime}$ & 251 & $2 x^{*}$ \\
\hline AR, Salta. A. Panseri, W. Reynoso, M. Sosa \& D. Hojsgaard 25 (CTES). & $23^{\circ} 00^{\prime}$ & $63^{\circ} 53^{\prime}$ & 341 & $2 x-3 x^{*}$ \\
\hline $\begin{array}{l}\text { AR, Salta, Dpto. San Martín. Río Conepoi. A. Panseri, W. Reynoso, M. Sosa } \\
\& \text { D. Hojsgaard } 24 \text { (CTES). }\end{array}$ & $22^{\circ} 06^{\prime}$ & $63^{\circ} 42^{\prime}$ & 511 & $2 x-3 x^{*}$ \\
\hline PA, Dpto. Boquerón. Schinini \& Palacios 25640 (CTES). & $20^{\circ} 50^{\prime}$ & $61^{\circ} 55^{\prime}$ & 310 & $2 x-3 x^{*}$ \\
\hline $\begin{array}{l}\text { PA, Dpto. Boquerón, Transchaco. A. Krapovickas, C. Cristóbla \& A. Schinini } \\
45430 \text { (CTES). }\end{array}$ & $20^{\circ} 38^{\prime}$ & $62^{\circ} 00^{\prime}$ & 330 & $2 x-4 x^{*}$ \\
\hline $\begin{array}{l}\text { PA, Dpto. Alto Paraguay, Sierra León. Perez de Molas \& G. Navarro } 9084 \\
\text { (CTES). }\end{array}$ & $19^{\circ} 40^{\prime}$ & $60^{\circ} 47^{\prime}$ & 302 & $2 x-4 x^{*}$ \\
\hline $\begin{array}{l}\text { AR, Salta, Dpto. Anta. El Quebrachal. V. Solís Neffa, G. Seijo, M. Grabiele \& } \\
\text { W. Reynoso } 1478 \text { (CTES, ESA, MO, SI). }\end{array}$ & $25^{\circ} 21^{\prime}$ & $64^{\circ} 01^{\prime}$ & 358 & $4 \mathrm{x}$ \\
\hline AR, Salta, Dpto. Anta. A. Panseri, W. Reynoso, M. Sosa \& D. Hojsgaard s/n. & $25^{\circ} 12^{\prime}$ & $63^{\circ} 59^{\prime}$ & 345 & $4 x^{*}$ \\
\hline $\begin{array}{l}\text { AR, Salta, el Tunal, Río Juramento. A. Panseri, W. Reynoso, M. Sosa \& D. } \\
\text { Hojsgaard } 28 \text { (CTES). }\end{array}$ & $25^{\circ} 14^{\prime}$ & $64^{\circ} 23^{\prime}$ & 437 & $4 x$ \\
\hline $\begin{array}{l}\text { BO, Dpto. Sta. Cruz, Prov. Chiquitos. V. Solis Neffa, G. Seijo, A. Schinini \& } \\
\text { R. Almada } 1315 \text { (CTES, BAB, LPB, SI). }\end{array}$ & $17^{\circ} 42^{\prime}$ & $61^{\circ} 14^{\prime}$ & 270 & $4 \mathrm{x}$ \\
\hline $\begin{array}{l}\text { BO, Dpto. Sta. Cruz, Prov. Chiquitos. San José de Chiquitos. V. Solís Neffa, } \\
\text { G. Seijo, A. Schinini \& R. Almada } 1285 \text { (CTES, LPB, SI). }\end{array}$ & $18^{\circ} 09^{\prime}$ & $60^{\circ} 50^{\prime}$ & 320 & $4 x$ \\
\hline $\begin{array}{l}\text { BO, Dpto. Sta. Cruz, Prov. Nuflo de Chaves. V. Solís Neffa, G. Seijo, M. } \\
\text { Grabiele \& W. Reynoso } 1546 \text { (CTES, HRB, K, LPB, MBM, SI). }\end{array}$ & $16^{\circ} 56^{\prime}$ & $61^{\circ} 51^{\prime}$ & 430 & $4 \mathrm{x}$ \\
\hline $\begin{array}{l}\text { BO, Dpto. Sta. Cruz, Prov. Ñuflo de Chaves. V. Solís Neffa, G. Seijo, M. } \\
\text { Grabiele \& W. Reynoso } 1547 \text { (CTES, LPB, SI, ZT). }\end{array}$ & $16^{\circ} 58^{\prime}$ & $61^{\circ} 51^{\prime}$ & 289 & $4 \mathrm{x}$ \\
\hline $\begin{array}{l}\text { BO, Dpto. Sta. Cruz, Prov. Chiquitos. V. Solís Neffa, G. Seijo, M. Grabiele \& } \\
\text { W. Reynoso } 1917 \text { (CTES, ASU, FCQ, LPB,MO, SI). }\end{array}$ & $18^{\circ} 09^{\prime}$ & $60^{\circ} 03^{\prime}$ & 383 & $4 x$ \\
\hline $\begin{array}{l}\text { BO, Dpto. Sta. Cruz, Prov. Chiquitos. V. Solís Neffa, G. Seijo, M. Grabiele \& } \\
\text { W. Reynoso } 1922 \text { (CTES, BAB, CESJ, GH, LPB, SI). }\end{array}$ & $18^{\circ} 06^{\prime}$ & $60^{\circ} 05^{\prime}$ & 382 & $4 \mathrm{x}$ \\
\hline $\begin{array}{l}\text { BO, Dpto. Sta. Cruz, Prov. Chiquitos. V. Solís Neffa, G. Seijo, M. Grabiele \& } \\
\text { W. Reynoso } 1927 \text { (CTES, FCQ, LPB, SI). }\end{array}$ & $17^{\circ} 57^{\prime}$ & $60^{\circ} 18^{\prime}$ & 426 & $4 x$ \\
\hline $\begin{array}{l}\text { BO, Dpto. Sta. Cruz, Prov. Chiquitos. V. Solís Neffa, G. Seijo, M. Grabiele \& } \\
\text { W. Reynoso } 1876 \text { (CTES, GH, LPB, SI). }\end{array}$ & $17^{\circ} 52^{\prime}$ & $60^{\circ} 28^{\prime}$ & 303 & $4 x$ \\
\hline $\begin{array}{l}\text { BO, Dpto. Sta. Cruz, Prov. Chiquitos. V. Solís Neffa, G. Seijo, A. Schinini \& } \\
\text { R. Almada } 1273 \text { (CTES, BAA, LPB, SI). }\end{array}$ & $17^{\circ} 47^{\prime}$ & $60^{\circ} 43^{\prime}$ & 268 & $4 x$ \\
\hline $\begin{array}{l}\text { BO, Dpto. Sta. Cruz, Prov. Chiquitos. San José de Chiquitos. V. Solís Neffa, } \\
\text { G. Seijo, A. Schinini \& R. Almada } 1278 \text { (CTES, LPB, MO, SI). }\end{array}$ & $17^{\circ} 54^{\prime}$ & $60^{\circ} 47^{\prime}$ & 454 & $4 \mathrm{x}$ \\
\hline $\begin{array}{l}\text { BO, Dpto. Sta. Cruz, Prov. Velasco. V. Solís Neffa, G. Seijo, M. Grabiele \& } \\
\text { W. Reynoso } 1749 \text { (CTES, JUA, LPB, NY, SI). }\end{array}$ & $16^{\circ} 54^{\prime}$ & $60^{\circ} 37^{\prime}$ & 324 & $4 x$ \\
\hline $\begin{array}{l}\text { BO, Dpto. Sta. Cruz, Prov. Chiquitos. V. Solís Neffa, G. Seijo, M. Grabiele \& } \\
\text { W. Reynoso } 1766 \text { (CTES, LPB, SI, MA). }\end{array}$ & $17^{\circ} 17^{\prime}$ & $60^{\circ} 37^{\prime}$ & 285 & $4 \mathrm{x}$ \\
\hline $\begin{array}{l}\text { BO, Dpto. Sta. Cruz, Prov. Chiquitos. V. Solís Neffa, G. Seijo, M. Grabiele \& } \\
\text { W. Reynoso } 1770 \text { (CTES, LPB, SI). }\end{array}$ & $17^{\circ} 40^{\prime}$ & $60^{\circ} 42^{\prime}$ & 285 & $4 \mathrm{x}$ \\
\hline
\end{tabular}




\section{Y. Lazzaroff et al. - Análisis citogeográfico en Turnera krapovickasii}

\begin{tabular}{|c|c|c|c|c|}
\hline Procedencia y número de colección & Lat. S & Long. $\mathrm{O}$ & Altitud (m.s.m.) & Ploidía \\
\hline $\begin{array}{l}\text { BO, Dpto. Sta. Cruz, Prov. Chiquitos. V. Solís Neffa, G. Seijo, M. Grabiele \& } \\
\text { W. Reynoso } 1777 \text { (CTES, LPB). }\end{array}$ & $17^{\circ} 47^{\prime}$ & $60^{\circ} 43^{\prime}$ & 279 & $4 x$ \\
\hline $\begin{array}{l}\text { BO, Dpto. Sta. Cruz, Prov. Chiquitos. Serranías de Chiquitos. V. Solís Neffa, } \\
\text { G. Seijo, M. Grabiele \& W. Reynoso } 1784 \text { (CTES, LPB). }\end{array}$ & $17^{\circ} 54^{\prime}$ & $60^{\circ} 47^{\prime}$ & 505 & $4 x$ \\
\hline $\begin{array}{l}\text { BO, Dpto. Sta. Cruz, Prov. Chiquitos. V. Solís Neffa, G. Seijo, M. Grabiele \& } \\
\text { W. Reynoso } 1796 \text { (CTES, LPB). }\end{array}$ & $18^{\circ} 07^{\prime}$ & $60^{\circ} 50^{\prime}$ & 331 & $4 x$ \\
\hline $\begin{array}{l}\text { BO, Dpto. Sta. Cruz, Prov. Chiquitos. V. Solís Neffa, G. Seijo, M. Grabiele \& } \\
\text { W. Reynoso } 1799 \text { (CTES, LPB, SI). }\end{array}$ & $18^{\circ} 09^{\prime}$ & $60^{\circ} 50^{\prime}$ & 810 & $4 x$ \\
\hline $\begin{array}{l}\text { BO, Dpto. Sta. Cruz, Prov. Chiquitos. V. Solís Neffa, G. Seijo, M. Grabiele \& } \\
\text { W. Reynoso } 1866 \text { (CTES, LPB, SI), }\end{array}$ & $18^{\circ} 16^{\prime}$ & $60^{\circ} 51^{\prime}$ & 299 & $4 x$ \\
\hline $\begin{array}{l}\text { BO, Dpto. Sta. Cruz, Prov. Chiquitos. V. Solís Neffa, G. Seijo, M. Grabiele \& } \\
\text { W. Reynoso } 1877 \text { (CTES, LPB, SI, HUEFS). }\end{array}$ & $17^{\circ} 52^{\prime}$ & $60^{\circ} 26^{\prime}$ & 366 & $4 x$ \\
\hline $\begin{array}{l}\text { BO, Dpto. Santa Cruz. Prov. Chiquitos. V. Solís Neffa, G. Seijo, M. Grabiele } \\
\& \text { W. Reynoso } 1888 \text { (CTES, LPB, SI) }\end{array}$ & $18^{\circ} 25^{\prime}$ & $59^{\circ} 50^{\prime}$ & 237 & $4 x$ \\
\hline $\begin{array}{l}\text { BO, Dpto. Sta. Cruz, Prov. Chiquitos. V. Solís Neffa, G. Seijo, M. Grabiele \& } \\
\text { W. Reynoso } 913 \text { (CTES, LPB) }\end{array}$ & $18^{\circ} 19^{\prime}$ & $59^{\circ} 35^{\prime}$ & 648 & $4 x$ \\
\hline $\begin{array}{l}\text { BO, Dpto. Sta. Cruz, Prov. Chiquitos. Roboré. V. Solís Neffa, G. Seijo, M. } \\
\text { Grabiele \& W. Reynoso } 1915 \text { (CTES, LPB, NY, SI). }\end{array}$ & $18^{\circ} 20^{\prime}$ & $59^{\circ} 44^{\prime}$ & 297 & $4 x$ \\
\hline $\begin{array}{l}\text { BO, Dpto. Sta. Cruz, Prov. Chiquitos. V. Solís Neffa, G. Seijo, M. Grabiele \& } \\
\text { W. Reynoso } 1932 \text { (CTES, ESA, JUA, LPB, NY, SI, SP). }\end{array}$ & $17^{\circ} 38^{\prime}$ & $61^{\circ} 20^{\prime}$ & 280 & $4 x$ \\
\hline $\begin{array}{l}\text { BO, Dpto. Santa Cruz. Prov. José Miguel de Velasco. V. Solís Neffa, G. } \\
\text { Seijo, A. Schinini \& R. Almada } 1266 \text { (CTES, LPB, SI) }\end{array}$ & $17^{\circ} 22^{\prime}$ & $60^{\circ} 40^{\prime}$ & 290 & $4 x$ \\
\hline $\begin{array}{l}\text { BO, Dpto. Santa Cruz. Prov. Chiquitos. V. Solís Neffa, G. Seijo, M. Grabiele } \\
\text { \& W. Reynoso } 1908 \text { (CTES, JUA, LPB, SI). }\end{array}$ & $18^{\circ} 38^{\prime}$ & $60^{\circ} 03^{\prime}$ & 331 & $4 x$ \\
\hline $\begin{array}{l}\text { BO, Dpto. Santa Cruz. Prov. Nuflo de Cháves. V. Solís Neffa, G. Seijo, M. } \\
\text { Grabiele \& W. Reynoso } 1545 \text { (CTES, K, LPB, MA, NY, SI). }\end{array}$ & $16^{\circ} 54^{\prime}$ & $61^{\circ} 49^{\prime}$ & 383 & $4 x$ \\
\hline PA, Dpto. Nueva Asunción. Gral E.A. Garay. S. Beck 9433. & $21^{\circ} 56^{\prime}$ & $60^{\circ} 41^{\prime}$ & 171 & $4 x$ \\
\hline
\end{tabular}

Finalmente, la distribución geográfica potencial actual de los citotipos de T. krapovickasii fue predicha mediante el modelado del nicho ecológico utilizando el programa DIVA-GIS (Hijmans et al. 2005).

\section{Resultados}

Recuentos cromosómicos y estimación del nivel de ploidia

Los resultados obtenidos en este trabajo mostraron que las poblaciones de T. krapovickasii son diploides $(2 \mathrm{n}=2 \mathrm{x}=10 ; 50 \%)$ y tetraploides $(2 \mathrm{n}=4 \mathrm{x}=20 ; 50 \%)$ (Fig. 2; Tabla 1). Asimismo, los resultados de la estimación del nivel de ploidía a partir de semillas, reveló que la mayoría de las poblaciones diploides $(42,42 \%$ del total de poblaciones analizadas) están constituidas por un solo citotipo, mientras que en otras poblaciones se detectó la presencia de individuos triploides $(2 n=3 x=15,4,55 \%)$ o tetraploides $(3,03 \%)$ en algunas poblaciones diploides. Sin embargo, hasta el momento, no se encontraron plantas adultas triploides o tetraploides en dichas poblaciones diploides. Todas las poblaciones tetraploides estaban constituidas por un solo citotipo.

\section{Distribución geográfica de los citotipos}

El análisis de la distribución geográfica de los citotipos de T. krapovickasii mostró que las poblaciones diploides están concentradas en el oeste del área de distribución de la especie. Dichas poblaciones se extienden desde los $19^{\circ} \mathrm{S}$ en Bolivia y se prolongan hacia el sur por el noroeste de Argentina siguiendo la franja oriental de las Sierras Subandinas hasta los $24^{\circ} \mathrm{S}$, y entre los $59^{\circ} \mathrm{W}$ y $64^{\circ}$ $\mathrm{W}$, en alturas que varían entre los 124 hasta los 1342 


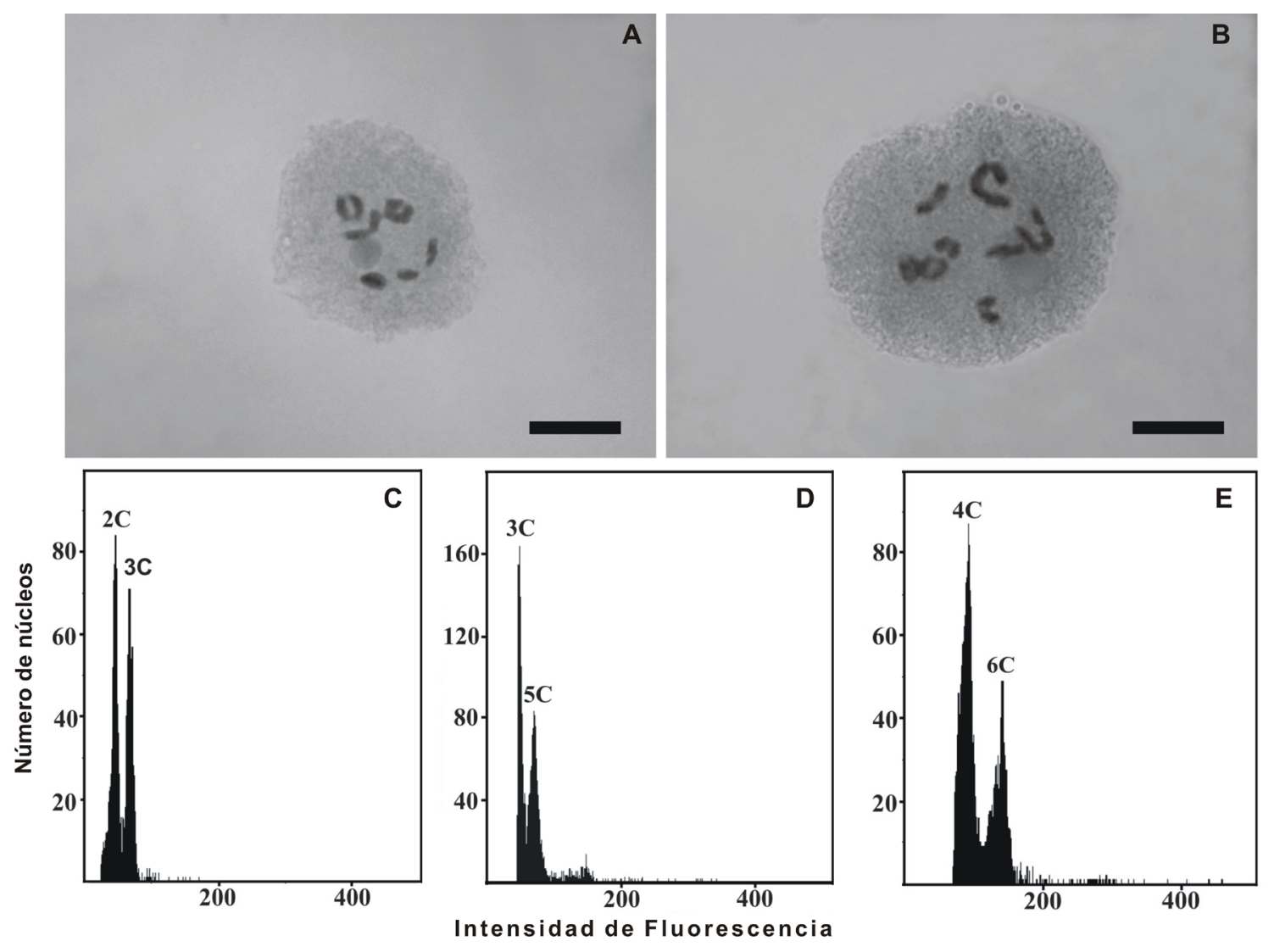

Fig. 2. Estimación del nivel de ploidía por meiosis y citometría de flujo en Turnera krapovickasii. A, citotipo dipoide $(2 n=2 x=10)$, diacinesis con $5 \mathrm{II}$. B, citotipo tetraploide $(2 n=4 x=20)$, diacinesis con $5 \mathrm{II}+2 \mathrm{IV}$. C, D y E histogramas obtenidos por citometría de flujo a partir de semillas. C, semilla con embrión diploide y endosperma triploide. $\mathrm{D}$, semilla con embrión triploide y endosperma pentaploide. E, semilla con embrión tetraploide y endosperma triploide hexaploide. Barra $5 \mu \mathrm{m}$.

m.s.n.m. Por otra parte, las poblaciones tetraploides ocupan áreas disyuntas, en el este y norte del área de distribución de la especie, en alturas que varían entre los 237 y 810 m.s.n.m. En el norte de Argentina y oeste de Paraguay se hallaron poblaciones mixtas $2 \mathrm{x}-3 \mathrm{x}$ y $2 \mathrm{x}-4 \mathrm{x}$, ubicadas en altitudes intermedias, no superiores a los 511 m.s.n.m. (Fig. 1).

El MANOVA realizado con las variables climaticas mostró diferencias significativas entre los citotipos $(\lambda$ Wilks $=8,61 ; \mathrm{p}<0.00001)$. Asimismo, el ANOVA mostró que 15 de las 20 variables climáticas analizadas, presentaron diferencias significativas entre citotipos $(\mathrm{p}<=0,05$, Tabla 2). El ACP basado en los datos bioclimáticos (Fig. 3) mostró que el primer eje de ordenación explica la mayor parte de la variación $(54,1$
\%) y separa a las poblaciones tetraploides de Bolivia y Paraguay (ubicadas hacia la derecha del diagrama), de las diploides y de un grupo más pequeño de poblaciones tetraploides de Argentina (ubicadas hacia la izquierda del diagrama). La isotermalidad, la temperatura mínima del mes más frío, la temperatura media del cuatrimestre más frío, las precipitaciones del mes más seco, las precipitaciones del cuatrimestre más seco y las precipitaciones del cuatrimestre más frío están correlacionadas positivamente con este eje, mientras que la estacionalidad de la temperatura, el rango de temperatura anual y la estacionalidad de la precipitaciones lo están negativamente. El segundo eje representa el 28,3\% de la variabilidad de los datos climáticos, y agrupa a la mayoría de 
Tabla 2. Altitud y variables bioclimáticas analizadas en el área geográfica de los citotipos de Turnera

krapovickasii. Se representa la media, desviación estándar y el rango de variación de cada variable. Ver referencias en Materiales y Métodos.

\begin{tabular}{|c|c|c|c|c|c|}
\hline Variable & $2 x$ & $2 x-3 x$ & $2 x-4 x$ & $4 x$ & $\boldsymbol{F}(\mathrm{ANOVA}) \boldsymbol{p}$ \\
\hline \multirow[t]{2}{*}{$\mathrm{BIO} 1\left(\mathrm{C}^{\circ}\right)$} & $22,75 \pm 1,31$ & $22,95 \pm 1,01$ & $24,47 \pm 0,59$ & $23,95 \pm 1,29$ & $5,01^{* *}$ \\
\hline & $19,53-24,75$ & $22,03-24,04$ & $24,06-24,89$ & $20,97-25,15$ & 0,004 \\
\hline \multirow[t]{2}{*}{$\mathrm{BIO} 2\left(\mathrm{C}^{\circ}\right)$} & $13,11 \pm 0,46$ & $12,74 \pm 0,20$ & $13,01 \pm 0,14$ & $13,07 \pm 0,39$ & 0,74 (NS) \\
\hline & $12,57-14,60$ & $12,53-12,93$ & $12,92-13,11$ & $12,61-13,78$ & 0,531 \\
\hline \multirow{2}{*}{$\begin{array}{c}\mathrm{BIO} 3(\mathrm{BIO} 2 / \\
\mathrm{BIO} 7^{* 100)}\end{array}$} & $56,36 \pm 4,40$ & $54,34 \pm 3,60$ & $61,02 \pm 3,26$ & $63,46 \pm 6,36$ & $9,64^{* *}$ \\
\hline & $51,29-67,17$ & $51,12-58,22$ & $58,71-63,33$ & $50,86-69,93$ & $<0.0001$ \\
\hline \multirow[t]{2}{*}{$\mathrm{BIO} 4\left(\mathrm{C}^{\circ}\right)$} & $355,24 \pm 55,98$ & $380,06 \pm 42,40$ & $314,01 \pm 26,56$ & $265,84 \pm 98,42$ & $7,07^{* *}$ \\
\hline & $200,51-423,51$ & $337,00-421,77$ & $295,23-332,78$ & $193,37-464,64$ & 0,000 \\
\hline \multirow[t]{2}{*}{$\mathrm{BIO5}\left(\mathrm{C}^{\circ}\right)$} & $33,21 \pm 1,34$ & $33,67 \pm 0,87$ & $34,30 \pm 0,00$ & $33,52 \pm 0,81$ & 0,94 (NS) \\
\hline & $30,20-35,50$ & $32,70-34,40$ & $34,30-34,30$ & $31,20-36,20$ & 0,426 \\
\hline \multirow[t]{2}{*}{$\mathrm{BIO6}\left(\mathrm{C}^{\circ}\right)$} & $9,83 \pm 2,15$ & $10,17 \pm 1,78$ & $12,95 \pm 0,92$ & $12,64 \pm 2,84$ & $6,82^{* *}$ \\
\hline & $4,90-13,50$ & $8,90-12,20$ & $12,30-13,60$ & $6,00-14,90$ & 0,001 \\
\hline \multirow[t]{2}{*}{$\mathrm{BIO} 7\left(\mathrm{C}^{\circ}\right)$} & $23,38 \pm 1,70$ & $23,50 \pm 1,18$ & $21,35 \pm 0,92$ & $20,88 \pm 2,99$ & $5,72^{* *}$ \\
\hline & $20,00-25,40$ & $22,20-24,50$ & $20,70-22,00$ & $18,70-27,10$ & 0,002 \\
\hline \multirow[t]{2}{*}{$\mathrm{BIO} 8\left(\mathrm{C}^{\circ}\right)$} & $26,12 \pm 1,32$ & $26,68 \pm 1,21$ & $27,21 \pm 0,18$ & $26,25 \pm 0,79$ & 0,84 (NS) \\
\hline & $23,40-28,65$ & $25,28-27,38$ & $27,08-27,33$ & $24,43-29,05$ & 0,476 \\
\hline \multirow[t]{2}{*}{$\mathrm{BIO} 9\left(\mathrm{C}^{\circ}\right)$} & $19,20 \pm 1,68$ & $19,22 \pm 2,33$ & $21,50 \pm 0,49$ & $21,50 \pm 2,89$ & $5,05^{\star *}$ \\
\hline & $16,45-22,17$ & $17,13-21,73$ & $21,15-21,85$ & $15,55-23,67$ & 0,003 \\
\hline \multirow[t]{2}{*}{$\mathrm{BIO} 10\left(\mathrm{C}^{\circ}\right)$} & $26,51 \pm 1,36$ & $26,98 \pm 0,75$ & $27,61 \pm 0,32$ & $26,58 \pm 0,75$ & 0,81 (NS) \\
\hline & $23,40-28,65$ & $26,12-27,43$ & $27,38-27,83$ & $24,47-29,05$ & 0,491 \\
\hline \multirow[t]{2}{*}{$\mathrm{BIO} 11\left(\mathrm{C}^{\circ}\right)$} & $18,00 \pm 1,60$ & $17,80 \pm 1,35$ & $20,12 \pm 0,99$ & $20,30 \pm 2,38$ & $7,10^{* *}$ \\
\hline & $14,68-21,18$ & $16,92-19,35$ & $19,42-20,82$ & $14,90-22,08$ & 0,000 \\
\hline \multirow[t]{2}{*}{$\mathrm{BIO} 12\left(\mathrm{~mm}^{3}\right)$} & $772,89 \pm 193,39$ & $813,67 \pm 285,10$ & $531,50 \pm 68,59$ & $970,88 \pm 211,72$ & $6,63^{* *}$ \\
\hline & $465,00-1308,00$ & $509,00-1074,00$ & $483,00-580,00$ & $598,00-1316,00$ & 0,001 \\
\hline \multirow[t]{2}{*}{$\mathrm{BIO} 13\left(\mathrm{~mm}^{3}\right)$} & $145,18 \pm 39,49$ & $153,33 \pm 59,16$ & $87,00 \pm 2,83$ & $164,24 \pm 30,07$ & $3,86^{\star *}$ \\
\hline & $77,00-224,00$ & $86,00-197,00$ & $85,00-89,00$ & $117,00-226,00$ & 0,013 \\
\hline \multirow[t]{2}{*}{$\mathrm{BIO} 14\left(\mathrm{~mm}^{3}\right)$} & $5,11 \pm 4,47$ & $5,33 \pm 1,53$ & $6,00 \pm 2,83$ & $15,67 \pm 7,93$ & $14,63^{\star *}$ \\
\hline & $1,00-25,00$ & $4,00-7,00$ & $4,00-8,00$ & $0,00-26,00$ & $<0,0001$ \\
\hline \multirow[t]{2}{*}{$\mathrm{BIO} 15$} & $82,97 \pm 10,05$ & $83,39 \pm 7,80$ & $67,77 \pm 11,36$ & $66,16 \pm 13,19$ & $11,18^{* *}$ \\
\hline & $56,05-98,06$ & $75,24-90,79$ & $59,75-75,80$ & $52,14-95,15$ & $<0,0001$ \\
\hline \multirow[t]{2}{*}{$\mathrm{BIO} 16\left(\mathrm{~mm}^{3}\right)$} & $405,18 \pm 106,88$ & $424,33 \pm 156,05$ & $236,50 \pm 0,71$ & $447,67 \pm 81,06$ & $3,59^{* *}$ \\
\hline & $212,00-618,00$ & $249,00-548,00$ & $236,00-237,00$ & $322,00-622,00$ & 0,019 \\
\hline \multirow[t]{2}{*}{$\mathrm{BIO} 17\left(\mathrm{~mm}^{3}\right)$} & $23,54 \pm 18,98$ & $20,33 \pm 5,13$ & $27,50 \pm 16,26$ & $74,91 \pm 33,94$ & $19,26^{\star *}$ \\
\hline & $11,00-105,00$ & $16,00-26,00$ & $16,00-39,00$ & $11,00-113,00$ & $<0,0001$ \\
\hline \multirow[t]{2}{*}{ BIO $18\left(\mathrm{~mm}^{3}\right)$} & $369,79 \pm 96,09$ & $405,67 \pm 171,67$ & $213,50 \pm 17,68$ & $362,88 \pm 68,72$ & 2,31 (NS) \\
\hline & $198,00-517,00$ & $210,00-531,00$ & $201,00-226,00$ & $284,00-622,00$ & 0,085 \\
\hline \multirow[t]{2}{*}{ BIO $19\left(\mathrm{~mm}^{3}\right)$} & $44,36 \pm 24,96$ & $31,33 \pm 13,87$ & $49,50 \pm 16,26$ & $104,79 \pm 47,85$ & $14,24^{* *}$ \\
\hline & $13,00-142,00$ & $16,00-43,00$ & $38,00-61,00$ & $11,00-153,00$ & $<0,0001$ \\
\hline \multirow[t]{2}{*}{ Altitud (m) } & $577,25 \pm 310,96$ & $390,67 \pm 113,14$ & $284,50 \pm 71,42$ & $348,64 \pm 109,47$ & $5,85^{\star *}$ \\
\hline & $132,00-1300,00$ & $310,00-520,00$ & $234,00-335,00$ & $171,00-803,00$ & 0,001 \\
\hline
\end{tabular}



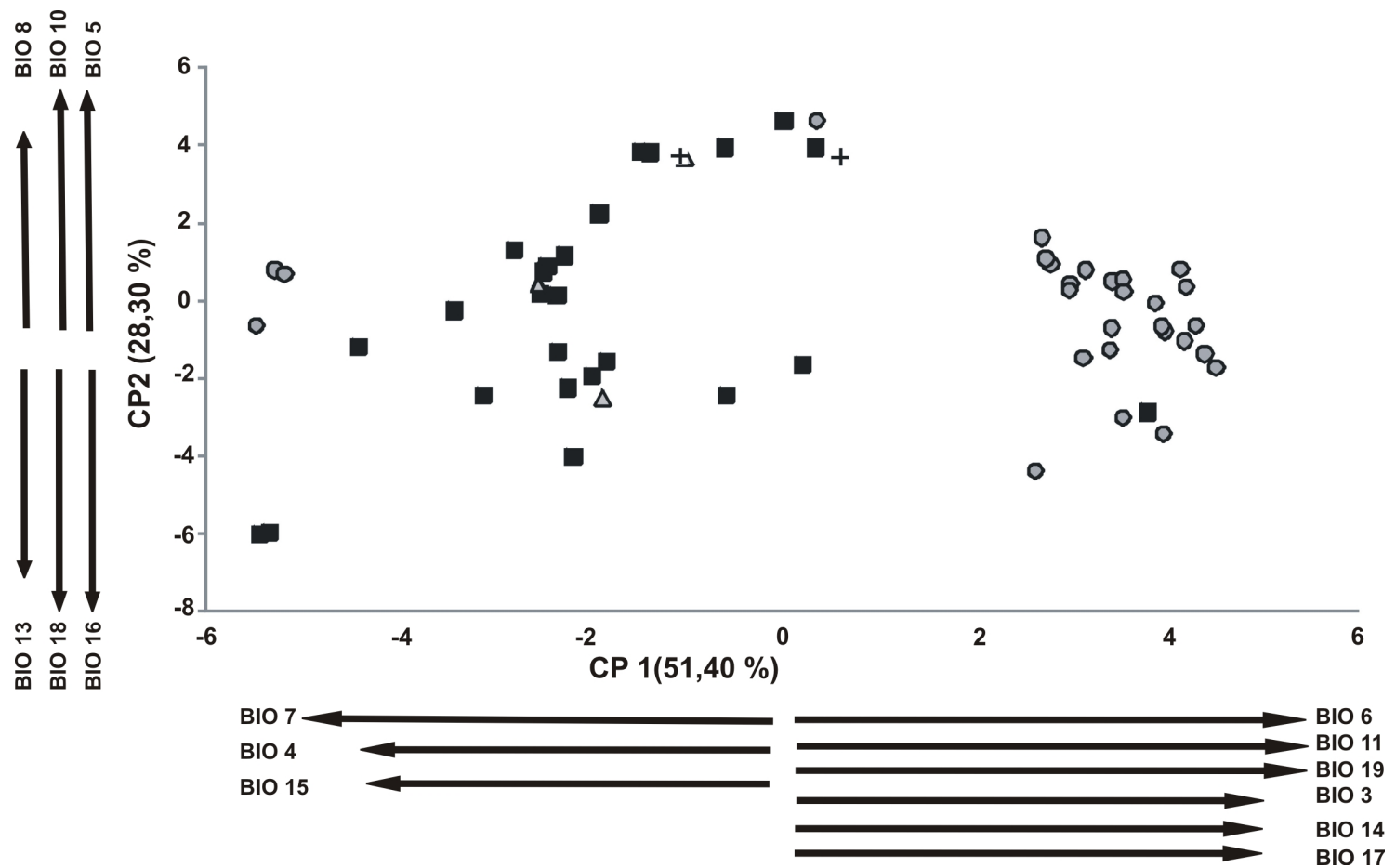

Fig. 3. Ordenamiento de las poblaciones de Turnera krapovickasii en el plano de los primeros componentes del análisis de Componentes Principales basado en datos bioclimáticos. Los distintos citotipos se indican con figuras: cuadrado $=$ diploide $(2 n=2 x=10)$; círculo $=$ tetraploide $(2 n=4 x=20)$; triángulo $=$ población mixta diploide - triploide $(2 n=3 x=15)$; cruz = población mixta diploide - tetraploide. Ver referencias en Materiales y Métodos.

las poblaciones mixtas, algunas diploides y una tetraploide. Las variables más correlacionadas con este eje son la temperatura máxima del mes más cálido, la temperatura media del cuatrimestre más húmedo y la temperatura media del cuatrimestre más cálido. La correlación cofenética fue alta $(r=0,974)$, indicando un buen ajuste entre la distancia euclideana entre las poblaciones en el diagrama de dispersión y la distancia en el espacio multidimensional original.

El análisis de modelado de la distribución potencial actual mostró que el área de mayor probabilidad de ocurrencia del citotipo diploide se encuentra al sureste de Bolivia, en la región de los bosques premontanos (Provincia Biogeográfica Chaqueña) que es transicional con las Yungas. A su vez, el área de mayor probabilidad de ocurrencia de los tetraploides se encuentra al este de Bolivia, en la Provincia Biogeográfica del Cerrado, disminuyendo esta probabilidad hacia las provincias del Pantanal y Chaqueña (Fig. 4).

\section{Discusión}

Recuentos cromosómicos y estimación del nivel de ploidia

Los resultados obtenidos en este trabajo confirman los recuentos obtenidos previamente los que demuestran que Turnera krapovickasii posee citotipos diploide y tetraploide (Fernández, 1987; Solís Neffa, 1996; Fernández \& Solís Neffa, 2004). Además, los resultados del análisis del nivel de ploidía por citometría de flujo evidenciaron que la mayoría de las poblaciones de esta especie están constituidas por un sólo citotipo, aunque también se detectaron algunos individuos triploides y tetraploides en las poblaciones diploides. Todos estos resultados ponen de manifiesto que la poliploidía es un fenómeno muy común en $T$. krapovickasii como también lo es en el género Turnera (Solís Neffa \& Fernández, 2000).

Por otra parte, aunque se cuenta con antecedentes de la ocurrencia de individuos triploides en 


\section{Y. Lazzaroff et al. - Análisis citogeográfico en Turnera krapovickasii}
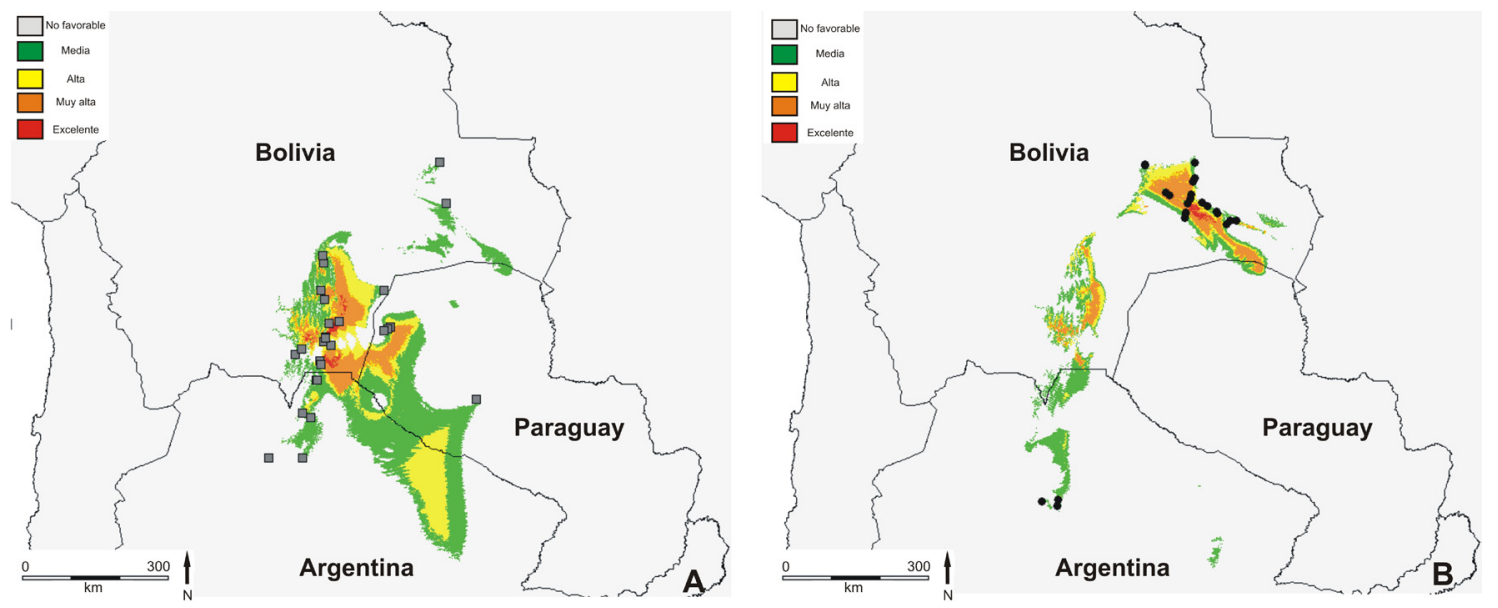

Fig. 4. Modelado de la distribución potencial de las poblaciones de Turnera krapovickasii analizadas. A: Poblaciones diploides. B: Poblaciones tetraploides.

las poblaciones naturales diploides de algunas especies de Turnera (Elías et al., 2011; Kovalsky \& Solís Neffa, 2012), los individuos triploides detectados en este trabajo, constituyen el primer hallazgo de poliploides impares en poblaciones naturales de T. krapovickasii. En algunos complejos autopoliploides, los triploides son raros o pueden estar ausentes (Lumaret et al. 1987; van Dijk et al. 1992), mientras que en otros, pueden aparecer con mayor frecuencia (Husband \& Schemske, 1998). Cuando están presentes, los triploides pueden formarse como resultado de la unión de gametos $n$ y $2 n$ dentro de poblaciones diploides o, por el cruzamiento de diploides y tetraploides (Ramsey \& Schemske, 1998). El hecho que los triploides de T. krapovickasii fueron detectados en las poblaciones diploides sumado a que, en estudios previos, se detectaron gametos no reducidos en individuos diploides provenientes de las mismas poblaciones (Fernández \& Arbo, 1990; Lazaroff et al., 2011), sustenta el origen de dichos triploides por poliploidización sexual unilateral a partir de la unión de gametos $n$ y $2 n$ de los diploides. Sin embargo, aunque en otras especies de Turnera se han encontrado plantas triploides, tanto en poblaciones naturales como en cruzamientos experimentales (Arbo \& Fernández, 1987; Fernández \& Arbo, 1990; Elías et al., 2010; Kovalsky \& Solís Neffa, 2012), en T. krapovickasii hasta el momento sólo se encontraron semillas con embriones triploides. El hecho que no se encontraran plantas adultas triploides en las poblaciones diploides podría deberse a que, como consecuencia de su baja frecuencia, los mismos no fueron detectados en este análisis. Además, también es posible que los embriones triploides hayan abortado en etapas tempranas del desarrollo como resultado del desbalance de la relación del nivel de ploidía del embrión y del endosperma o el radio materno: paterno (bloqueo triploide) como fuera propuesto para otras especies (Ramsey \& Schemske, 1998; Köhler et al., 2011). Por otra parte, los tetraploides hallados en las poblaciones diploides sugieren que la poliploidización sexual bilateral a partir de la unión de dos gametos $2 n$ de los diploides, también ocurriría con cierta frecuencia en las poblaciones diploides de T. krapovickasii.

\section{Distribución geográfica de los citotipos}

Los diferentes citotipos de los complejos poliploides muestran, frecuentemente, marcadas diferencias en su distribución geográfica (Favarger, 1967; Stebbins, 1971; Brunsberg, 1977; Lewis, 1980; Levin, 1983, 2002; Soltis, 1984; van Dijk et al., 1992; Husband \& Schemske, 1998; Kessler et al., 2014). En el género Turnera, las investigaciones llevadas a cabo en el complejo autopoliploide T. sidoides demostraron que el citotipo diploide posee una distribución más restringida, los tetraploides poseen una distribución amplia ocupando gran parte del área de las subespecies, los hexaploides generalmente están restringidos a 
regiones marginales, mientras que los octoploides y poliploides impares son raros (Solís Neffa \& Fernández, 2001; Solís Neffa et al., 2004; Elías et al., 2011). Por otra parte, en T. hassleriana Urban, T. subulata Smith y T. scabra Millspaugh, los citotipos diploide y autotetraploide (Fernández, 1987; Shore \& Barrett, 1986; Barrett \& Shore, 1987; Solís Neffa \& Fernández, 1993; Solís Neffa, 1996) presentan áreas geográficas diferentes, aunque tanto la frecuencia de diploides y tetraploides, como sus patrones de distribución geográfica varían entre las especies. En T. hassleriana la única población diploide encontrada hasta el momento corresponde a una accesión de Bolivia mientras que las tetraploides son accesiones de Paraguay (Fernández, 1987; Solís Neffa \& Fernández, 1993). En T. subulata, la mayoría de las poblaciones estudiadas son tetraploides, siendo las poblaciones diploides y tetraploides simpátricas en parte de su área (Fernández, 1987; Shore \& Barrett, 1986; Barrett \& Shore, 1987; Solís Neffa \& Fernández, 1993; Solís Neffa, 1996). Finalmente, en T. scabra el $40 \%$ de las poblaciones estudiadas son diploides y continentales, mientras que el $60 \%$ restante corresponden a poblaciones insulares tetraploides (Fernández, 1987; Shore \& Barrett, 1986; Barrett \& Shore, 1987). Los resultados de este trabajo mostraron que en T. krapovickasii los diploides y tetraploides se encuentran en igual frecuencia, las poblaciones diploides en el noroeste de Argentina, sureste de Bolivia y oeste de Paraguay, mientras que las tetraploides se encuentran en el este de Bolivia y en el noroeste de Argentina. Se ha sugerido que la variación en la frecuencia de poliploides entre grupos taxonómicos afines sería el resultado de las diferentes predisposiciones de dichos taxones para la evolución por poliploidía o de la diferencia en el tiempo transcurrido para acumular poliploides (Meyers \& Levin 2006). Ambas hipótesis podrían explicar las diferencias en la frecuencia de los citotipos entre T. krapovickasii y las otras especies de Turnera con citotipos diploide y autotetraploide. En primer término, estudios previos en el género Turnera demostraron que las especies analizadas producen diferentes proporciones de gametos no reducidos $2 n$ y $4 n$ (Fernández et al., 2010; Panseri et al., 2008; Kovalsky \& Solís Neffa, 2012; Lazaroff et $a l .$, inéd.), lo que sugiere que las especies tendrían diferentes predisposiciones a la poliploidización.
Por otra parte, teniendo en cuenta la abundancia relativa de los poliploides en comparación con sus ancestros diploides es posible estimar la edad de un complejo poliploide. Sobre la base de este criterio Stebbins (1971) reconoció cinco estados: inicial, joven, maduro, declinante y relictual. De acuerdo con ello, T. krapovickasii y T. scabra serían complejos poliploides jóvenes, en los que el citotipo diploide está todavía ampliamente distribuido, mientras que los tetraploides se han distribuido más allá del límite de los diploides; mientras que el complejo $T$. sidoides y $T$. subulata serían complejos maduros en los que los diploides son relictuales y los tetraploides están ampliamente distribuidos. Estos patrones de distribución sugieren que el tiempo transcurrido para acumular poliploides difiere entre las especies de Turnera.

Asimismo, diversas hipótesis podrían explicar las diferencias en la distribución de los citotipos diploide y tetraploide de T. krapovickasii. Los primeros estudios sobre el significado de la variación geográfica de los niveles de ploidía enfatizaron su relación con la latitud (Hagerup, 1932; Tischler, 1935; Stebbins, 1971; Grant, 1989). Esta relación ha sido interpretada como una adaptación de los poliploides, en general, a condiciones climáticas más extremas (Lewis, 1980). El área de distribución de T. krapovickasii presenta características ecológicas muy diversas debido a su topografía variable y a su ubicación en una zona de transición climática (Killeen et al., 1993; Ribera Arismendi, 1993; Navarro \& Maldonado, 2002). A lo largo del espectro latitudinal, esta región presenta un clima tropical en el norte y subtropical hacia el sur, variando de húmedo en el este, a semiárido y árido en el oeste y suroeste (Ribera Arismendi, 1993). En T. krapovickasii, aunque no se observa una tendencia al aumento de la frecuencia de los tetraploides con el incremento de la latitud, la distribución de los citotipos sería el resultado de diferencias adaptativas a las condiciones ambientales ya que el ACP basado en los datos bioclimáticos mostró que existe una asociación significativa entre la distribución de los citotipos y las condiciones climáticas de la región. Asimismo, el análisis de modelado de la distribución potencial actual reveló que los citotipos poseen diferentes preferencias de hábitats. Las poblaciones diploides, que ocupan un área continua, crecen en lugares de mayor 


\section{Y. Lazzaroff et al. - Análisis citogeográfico en Turnera krapovickasii}

altitud así como más fríos y húmedos en la región de los bosques premontanos de la provincia Chaqueña. En esta región, las precipitaciones varían desde $500 \mathrm{~mm}$ en el occidente de la planicie y en un gradiente creciente hacia el este. La época seca varía desde cuatro hasta ocho meses y la temperatura media anual varía desde $22{ }^{\circ} \mathrm{C}$ al pie de la Cordillera hasta $26^{\circ} \mathrm{C}$ en el interior del Chaco (Ramella \& Spichiger, 1989; Killeen et al., 1993; Navarro \& Maldonado, 2002). Los tetraploides, en cambio, ocupan áreas disyuntas, aunque la mayoría de las poblaciones se encuentra en la provincia biogeográfica del Cerrado cuyo clima es marcadamente pluviestacional y posee una época seca de por lo menos tres meses. Las precipitaciones anuales están por encima de 1000 $\mathrm{mm}$ al año y la temperatura promedio anual es de alrededor de $22^{\circ} \mathrm{C}$ (Ramella \& Spichiger, 1989; Killeen et al., 1993; Navarro \& Maldonado, 2002). Un número menor de poblaciones tetraploides fueron encontradas en el sur del área de distribución de la especie que presenta un clima más cálido y con escasas precipitaciones.

El hallazgo de poblaciones tetraploides en los extremos norte y sur del área de T. krapovickasii, sumado a las evidencias citogenéticas y moleculares (Lazaroff et al., ined.), sugiere que los tetraploides se habrían originado por autopoliploidía de manera independiente a partir de poblaciones diploides distribuidas en las áreas marginales de los diploides. Los tetraploides posteriormente habrían expandido sus áreas hasta alcanzar los limites actuales de T. krapovickasii.

El patrón de distribución de los citotipos detectado en Turnera krapovickasii sustenta la hipótesis de que el rango de expansión asociado con la poliploidía juega un papel importante en la historia evolutiva de esta especie como también fuera propuesto para otras especies del género (Solís Neffa \& Fernández, 2001; Elías et al., 2011).

\section{Agradecimientos}

Este trabajo fue financiado por proyectos de la Secretaría General de Ciencia y Técnica (UNNE, PI-17 F189). E. M. S. Moreno es becaria Postdoctoral de CONICET-UNNE. V. G. Solís Neffa es miembro de la Carrera del Investigador Científico de CONICET.

\section{Bibliografía}

ADAMS, K. L. \& J. F. WENDEL. 2005a. Polyploidy and genome evolution in plants: Genome studies and molecular genetics. Curr. Opin. Pl. Biol. 8: 135-141.

ADAMS, K. L. \& J. F. WENDEL. 2005b. Novel patterns of gene expression in polyploid plants. Trends Genet. 21: 539-543.

ARBO, M. M. 2005. Estudios sistemáticos en Turnera (Turneraceae). III. Series Anomalae y Turnera. Bonplandia 14: 115-318.

ARBO, M. M. \& A. FERNÁNDEZ. 1983. Posición taxonómica, citología y palinología de tres niveles de ploidía de Turnera subulata Smith. Bonplandia 5: 211-216.

ARBO, M. M. \& A. FERNÁNDEZ. 1987. Cruzamientos intra e interespecíficos en Turnera, serie Canaligerae. Bonplandia 6: 85-100.

ARBO, M. M. \& S. M. ESPERT. 2009. Morphology, phylogeny and biogeography of Turnera (Turneraceae). Taxon 58: 457-467.

BARRETT, S. C. H. 1978. Heterostyly in a tropical weed: the reproductive biology of Turnera ulmifolia complex (Turneraceae). Canad. J. Bot. 1713-1725.

BARRETT, S. C. H. \& J. SHORE. 1987. Variation and evolution of breeding systems in the Turnera ulmifolia L. Complex (Turneraceae). Evolution 41: 340-354.

BRUNSBERG, K. 1977. Biosystematics of the Lathyrus pratensis complex. Opera Bot. Belg. 42: 1-78.

CABRERA, A. L. 1976. Regiones fitogeográficas argentinas. En: Kugler, W. F. (ed.), Enciclopedia Argentina de Agricultura y Jardinería, II, ACME, Buenos Aires, pp. 1-85.

CABRERA, A. L. \& A. WILLINK. 1973. Biogeografía de América Latina. Monografía No 13. Secretaría General de la Organización de los Estados Americanos. Programa Regional de Desarrollo Científico y Tecnológico, Washington, D.C. pp. 120.

CHEN, Z. J. \& Z. NI. 2006. Mechanisms of genomic rearrangements and gene expression changes in plant polyploids. Bioessays 28: 240-252.

DI RIENZO, J. A., F. CASANOVES, M. G. BALZARINI, L. GONZÁLEZ, M. TABLADA \& C. W. ROBLEDO. 2014. iNFOsTAT VERSION 2014. Grupo InfoStat, FCA, Universidad Nacional de Córdoba, Argentina. http://www.infostat.com.ar.

DURAND, D. \& R. HOBERMAN. 2006. Diagnosing duplications - can it be done? Trends Genet. 22: 156-164.

ERHENDORFER, F. 1980. Polyploidy and distribution. In: LEWIS, W.H., ed. Polyploidy, biological relevance. New York: Plenum Press, 45-60.

ELÍAS, G., M. SARTOR \& V. G. SOLÍS NEFFA. 2011. Patterns of cytotype variation of Turnera sidoides 
subsp. pinnatifida (Turneraceae) in mountain ranges of central Argentina. J. Plant Res. 124: 25-34.

ELÍAS G., M. SARTOR \& V. G. SOLÍS NEFFA. 2011. Patterns of cytotype variation of Turnera sidoides subsp. pinnatifida (Turneraceae) in mountain ranges of central Argentina. J. Plant Res. 124: 25-34.

FAVARGER, C. 1967. Cytologie et distribution des plantes. Biol. Rev. 42: 163-206.

FERNÁNDEZ, A. 1973. El ácido láctico como fijador cromosómico. Bol. Soc. Argent. Bot. 15: 287-290.

FERNÁNDEZ, A. 1987. Estudios cromosómicos en Turnera y Piriqueta (Turneraceae). Bonplandia 6: $1-21$.

FERNÁNDEZ, A. \& M. M. ARBO. 1990. Gametas no reducidas y relaciones genómicas en tres especies de Turnera (Turneraceae). Darwiniana 30: 21-26.

FERNÁNDEZ,A. \& V. G. SOLÍS NEFFA. 2004. Genomic relationships between Turnera krapovickasii $(2 \mathrm{x}, 4 \mathrm{x})$ and Turnera ulmifolia (6x) (Turneraceae, Turnera). Caryologia 57: 45-51.

FERNÁNDEZ, A., H. REY \& V. G. SOLÍS NEFFA. 2010. Evolutionary realtionships between Turnera grandiflora and the octoploid T. fernandezii (Turneraceae). Ann. Bot. Fen. 47: 321-329.

GENTRY, A. H. 1982. Neotropical floristic diversity: phytogeographical connections between Central and South America, Pleistocene climatic fluctuations, or an accident of the Andean orogeny? Ann. Missouri Bot. Gard. 69: 557-593.

GENTRY, A. H. \& C. H. DODSON. 1987. Diversity and biogeography of Neotropical vascular epiphytes. Ann. Missouri Bot. Gard. 74: 205-233.

GRANT, V. 1989. Especiación vegetal. Ed. Limusa. Méjico, pp. 587.

HAGERUP, O. 1932. Ueber polyploidie in beziehung zu klima, oekologie und phylogenie. Hereditas 16 : 19-40.

HIJMANS, R. J., L. GUARINO, C. BUSSINK, P. MATHUR, M. CRUZ, I. BARRANTES \& E. ROJAS. 2004. Diva-Gis. Sistema de Información Geográfica para el Análisis de Datos de Distribución de Espécies.

HIJMANS, R. J., S. E. CAMERON, J.L. PARRA, P.G. JONES \& A. JARVIS. 2005. Very high resolution interpolated climate surfaces for global landa reas. Int. J. Climatol. 25: 1965-1978.

HUSBAND, B. C. \& D. W. SCHEMSKE. 1998. Cytotype distribution at a diploid-tetraploid contact zone in Chamerion (Epilobium) angustifolium (Onagraceae). Am. J. Bot. 85: 1688-1694.

HUSBAND, B. C., S. J. BALDWIN \& J. SUDA. 2013. The Incidence of polyploidy in natural plant populations: Major patterns and evolutionary processes. En: Leitch I. J., J. Greilhuber, J. Doležel, J. F. Wendel, editors. Plant Genome Diversity 2:
Physical Structure, Behaviour and Evolution of Plant Genomes. Springer; Wien. pp. 255-276.

INFOSTAT. 2008. InfoStat, version 2008. Grupo InfoStat, FCA. National University of Córdoba, Argentina.

KESSLER, M., A. KÜHN, V. G. SOLÍS NEFFA \& I. HENSEN. 2014. Complex geographical distribution of ploidy levels in Polylepis australis (Rosaceae), an endemic tree line species in Argentina. Int. J. Plant Sci. DOI: $10.1086 / 677649$.

KILLEEN, T. J., E. GARCÍA \& S. G. BECK. 1993. Guía de árboles de Bolivia. Herbario Nacional de Bolivia \& Missouri Botanical Garden.

KÖHLER, C., O. MITTELSTEN SCHEID \& A. ERILOVA. 2011. The impact of the triploid block on the origin and evolution of polyploid plants. Trends in Genetics 26: 142-148.

KOVALSKY, I. E. \& V. G. SOLÍS NEFFA. 2012. Evidence of $2 n$ microspore production in a natural diploid population of Turnera sidoides subsp. carnea and its relevance in the evolution of the $T$. sidoides (Turneraceae) autopolyploid complex. J. Pl. Res. 125: 725-734.

LAZAROFF, Y., A. FERNÁNDEZ \& V. G. SOLÍS NEFFA. 2009. Estudios cromosómicos en Turnera krapovickasii (Turneraceae). Bol. Soc. Argent. Bot. Volumen 44

LAZAROFF, Y., A. FERNÁNDEZ \& V. G. SOLÍS NEFFA. 2011. Análisis de la producción y frecuencia de gametos no reducidos en poblaciones diploides de Turnera krapovickasii. J. Basic Appl. Genet. Volumen XLI.

LEVIN, D. A. 1983. Polyploidy and novelty in flowering plants. Am. Nat. 122: 1-25.

LEVIN, D. A. 2002. The role of chromosome change in plant evolution. New York: Oxford University Press.

LEWIS, W. H. 1980. Polyploidy in species population. In: LEWIS, W.H., ed. Polyploidy, biological relevante, New York: Plenum Press, 103-144.

LÓPEZ, A., A. FERNÁNDEZ, \& J. S. SHORE. 2013. Inferences on the origins of polyploid Turnera species (Passifloraceae) based on molecular data. Botany 91: 167-175.

LUMARET, R., J. L. GUILLERM, J. DELAY, A. AIT IHAJ LOUTFI, J. IZCO \& M. JAY. 1987. Polyploidy and habitat differentiation in Dactylis glomerata L. from Galicia (Spain). Oecologia 73: 436-446.

MADLUNG, A. 2013. Polyploidy and its effect on evolutionary success: old questions revisited with new tools. Heredity 110: 99-104.

MEYERS L. A. \& D. A. LEVIN. 2006. On the abundance of polyploids in flowering plants. Evolution 60: 1198-1206.

MORAES, M. \& S. G. BECK. 1992. Diversidad floristica de Bolivia. En: M. Marconi (ed.). Conservación de la Diversidad Biològica en Bolivia, p. 73-111. Centro 


\section{Y. Lazzaroff et al. - Análisis citogeográfico en Turnera krapovickasii}

de datos para la conservación, La Paz (Bolivia).

MORRONE, J. J. 2001. Biogeografía de América Latina y el Caribe. M\&T-Manuales y Tesis SEA, Zaragoza.

NAVARRO, G. \& M. MALDONADO. 2002. Geografía Ecológica de Bolivia: Vegetación y Ambientes Acuátcos. Editorial: Centro de Ecología Simón I. Patiño-Departamento de Difusión. Cochabamba, Bolivia.

OSBORN, T. C., D. V. BUTRULLE, A. G. SHARPE, K. J. PICKERING, I. A. PARKIN, J. S. PARKER \& D. J. LYDIATE. 2003. Detection and effects of a homeologous reciprocal transposition in Brassica napus. Genetics 165: 1569-1577.

PANSERI, A. F., J. G. SEIJO \& V. G. SOLÍS NEFFA. 2008. Análisis de la producción y frecuencia de microsporas no reducidas en diploides de Turnera sidoides (Turneraceae). Bol. Soc. Argent. Bot. 43: 95-101.

RAMAN, V. S. \& P. C. KESAVAN. 1964. Meiosis and nature of polyploidy in Turnera ulmifolia. J. Indian Bot. Soc. 43: 495-499.

RAMELLA, L. \& R. SPICHIGER. 1989. Interpretación preliminar del medio físico y de la vegetación del Chaco Boreal. Contribución al estudio de la flora y de la vegetación del Chaco. I. Candollea 44: 639680.

RAMSEY, J. \& D. W. SCHEMSKE. 1998. Pathways, mechanisms, and rates of polyploid formation in flowering plants. Annu. Rev. Ecol. System. 29: 467501.

REYNOSO, W. L., V. SOLÍS NEFFA \& A. FERNÁNDEZ. 2004. "Análisis preliminar de la distribución geográfica de los citotipos de Turnera krapovickasii (Turneraceae)". VIII Comunicaciones Científicas y Tecnológicas de la UNNE.

RIBERA ARISMENDI, M. 1993. Regiones ecológicas. En: M. Marconi (ed.) Conservación de la Diversidad Biológica en Bolivia, p. 9-71. Centro de datos para la conservación, La Paz (Bolivia).

SHORE, J. S. 1991a. Chromosomal evidence for autotetraploidy in the Turnera ulmifolia complex (Turneraceae). Can. J. Bot. 69: 1302-1308.

SHORE, J. S. 1991b. Tetrasomic inheritance and isozyme variation in T. ulmifolia vars. elegans Urb. and intermedia Urb. (Turneraceae). Heredity 66: 305312.

SHORE, J. S. \& S. C. H. BARRET. 1986. Genetic modification of dimorphic incompatibility in the Turnera ulmifolia L. complex (Turneraceae). Canad. J. Genet. Cytol. 28: 796 - 807.
SOLÍS NEFFA, V. G. 1996. Cariotipos en Turnera (Turneraceae). Bonplandia 9 (1-2): 121-127.

SOLÍS NEFFA, V. G. \& A. FERNÁNDEZ. 1993. Estudios cromosómicos en especies de Turnera (Turneraceae). Bonplandia 7 (1-4): 101-118.

SOLÍS NEFFA, V. G. \& A. FERNÁNDEZ. 2000. Chromosome studies in Turnera (Turneraceae). Genet. Mol. Biol. 23: 925-930.

SOLIS NEFFA, V. G. \& A. FERNÁNDEZ. 2001. Cytogeography of the Turnera sidoides L. complex (Turneraceae, Leiocarpae). Bot. J. Linn. Soc .137: 189-196.

SOLÍS NEFFA, V. G., A. F. PANSERI, W. REYNOSO \& J. G. SEIJO. 2004. Variación en el color de flores y números cromosómicos en el Noroeste del área de distribución de Turnera sidoides (Turneraceae). Bonplandia 13: 117-128.

SOLTIS, D. E. 1984. Autopolyploidy in Tolmiea menziesii (Saxifragaceae). Am. J. Bot. 71: 1171-1174.

SOLTIS, D. E., P. S. SOLTIS \& J. A. TATE. 2004. Advances in the study of polyploidy since plant speciation. New Phytol. 161: 173-191.

STEBBINS, G. L. 1971. Chromosomal evolution in higher plants (London: Addison-Wesley Press).

TISCHLER, G. 1935. Die bedeutung der polyploidie für die verbreitung der Angiospermen, erläutert an den arten Schleswig-Holsteins, mit Ausblicken auf andere florengebiete. Bot. Jahrb. Syst. 67: 1-36.

UDALL, J. A. \& J. F. WENDEL. 2006. Polyploidy and crop improvement. Crop Sci. 46: S3-S14.

URBAN, I. 1883. Monographie der familie der Turneraceen. Jahrb. Königl. Bot. Gart. Berlin 2: $1-152$

VAN DIJK, P., M. HARTOG \& W. VAN DELDEN. 1992. Single cytotype areas in autopolyploid Plantago media L. Biol. J. Linn. Soc. 46: 315-331.

WENDEL, J. \& J. DOYLE. 2005. Polyploidy and evolution in plants. P. 97-117. En R.J. Henry (ed.) Plant diversity and evolution: Genotypic and phenotypic variation in higher plants. $\mathrm{CAB}$ International.

YOUNG, K. E.; C. ULLOA ULLOA, J. L. LUTEYN \& S. KNAPP. 2002. Plant evolution and endemism in Andean South America: an introduction. Bot. Rev. 68: 4-21.

Recibido el 24 de julio de 2015, aceptado el 23 de septiembre de 2015. 
